\title{
ON THE ENERGY OF BICYCLIC SIGNED DIGRAPHS
}

\author{
MEHTAB KHAN AND RASHID FAROOQ
}

Abstract. Among unicyclic digraphs and signed digraphs with fixed number of vertices, the digraphs and signed digraphs with minimal and maximal energy are already determined. In this paper we address the problem of finding bicyclic signed digraphs with extremal energy. We obtain minimal and maximal energy among all those $n$-vertex bicyclic signed digraphs which contain vertex-disjoint signed directed cycles, $n \geqslant 4$.

Mathematics subject classification (2010): 05C35, 05C50.

Keywords and phrases: Energy of digraph, bicyclic signed digraph, spectra of a graph.

\section{REFERENCES}

[1] B. D. Acharya, Spectral criterion for the cycle balance in networks, J. Graph Theor., 4, (1980), $1-11$.

[2] K. A. Germina, K. S. Hameed, T. Zaslavsky, On products and line graphs of signed graphs, their eigenvalues and energy, Linear Algebra Appl., 435, (2010), 2432-2450.

[3] I. Gutman, The energy of a graph, Ber. Math. Stat. Sekt. Forschungszentrum Graz, 103, (1978), $1-22$.

[4] M. Khan, R. Farooq, A. A. Siddiqui, On the extremal energy of bicyclic digraphs, J. Math. Inequal., 9, 3 (2015), 799-810.

[5] Monsalve, J. Rada, Bicyclic digraphs with maximal energy, Appl. Math. Comput., 280, (2016), $124-131$.

[6] I. PEÑA, J. RADA, Energy of digraphs, Linear Multilinear A., 56, 5 (2008) 565-579.

[7] S. Pirzada, M. A. Bhat, Energy of signed digraphs, Discrete Applied Math., 169, (2014), 195-205. 